\title{
Teaching Science Concepts using LITEE Case Studies
}

\author{
Shiva K. Sankar, Northwestern University \\ Chetan S. Sankar, Department of Management \\ P.K. Raju, Department of Mechanical Engineering \\ Auburn University
}

\section{Project Goals}

The NSF, in its Shaping the Future document (NSF, 1996), declared that improved science, mathematics, engineering, and technology education is central to shaping America's future. They expect that it will be increasingly necessary that citizens have a substantial understanding of the methods and content of science and technology and some understanding of their potential and limitations, as well as their interconnectedness.

Science, technology, engineering, and math (STEM) education is seen as important not only for researchers but also for a diverse, technologically literate workforce and for an educated and informed citizenry (National Science Board, 2000; Cost Engineering, 1996). Despite the observation that America's basic research in science, math, and engineering is world class, its education is still not mature. Too many students leave STEM courses because they find them dull and unwelcoming. Too many new teachers enter school systems unprepared, without really understanding the relevance of STEM courses to the development of scientific and technological literacy in students. They also lack the excitement of discovery and the confidence and ability to help motivate children to develop interest in STEM courses. Too many graduates go out into the workforce ill prepared to solve real-world problems in a cooperative way, lacking the skills and the motivation to continue learning (NSF, 1996). Therefore, the first goal of this project is to develop course material to show the relevance of STEM education in solving real-world engineering and technological problems.

The teaching of domain-specific knowledge has long been recognized to be the primary objective of school and college education, but many students lack the breadth of knowledge and skills that are fundamental to the practice of their profession (Aldridge, 1994; Leidner and Jarvenpaa, 1993; Fergusson, 1992). There is now a growing realization among educators of the need to put a greater emphasis on imparting higher-level cognitive skills (e.g., reasoning, critical thinking, decision making, problem identification, and problem solving). A variety of national reports (Bok, 1986; Boyer, 1987, NSF, 1996) have also stressed the importance of teaching such skills to all levels of students. The learning experience must move from lecture as a dominant mode to include a significant level of active learning approaches. Cooperative learning approaches and other contextual experiential learning must be integrated into the classroom (Sheila, 1992). The relative neglect of teaching of higher-level cognitive skills is due to two illfounded assumptions: (a) that these skills cannot be taught and (b) that they need not be taught. Evidence is accumulating that both assumptions are wrong: higher-level cognitive skills can be improved by training, and it is not safe to assume that such skills will emerge automatically as a matter of development or maturation (Nickerson, 1994; Hingorani, Sankar, and Kramer, 1997).

Proceedings of the 2004 American Society for Engineering Education Annual Conference \& Exposition, Copyright @2004, American Society for Engineering Education 
Therefore, the second goal of this project is to develop course material to improve the higher-level cognitive skills of the students.

Information technologies provide access to vast information sources to support discovery-based educational experiences safely, and to more aggressively support peer-to-peer education (Wulf, 1998). Doyle Daves, Jr., Dean of the School of Science, Rensselaer Polytechnic Institute, wrote (NSF, 1996):

As the tools of the information, communication, and computing technology revolution become integrated into the educational process, the traditional classroom reliance on the lecture format becomes increasingly anachronistic. The essence of the new technology is empowerment of the user, inevitably in the use of computer based technologies, learning becomes both active and under the control of the learner. Similarly, when students are actively engaged in the learning process using multi-media and information technology tools, almost inevitably, they work together in groups or teams sharing insights and experiences and, in the process, learn teamwork, communication, and organizational skills as well as the subject matter.

Television, computers, and video games appear to have modified significantly the ways that young people learn and are willing to learn. Therefore, the third goal of this project is to integrate information technologies into the course material.

\section{Methodology to Meet the Project Goals}

A review of literature identified that the teaching methodologies of lectures, experimental laboratory, design projects, case studies, games, and internships could achieve the project goals. An analysis showed that the case study method of instruction was the best candidate for meeting the goals (Mbarika, Raju and Sankar, 2003).

During 1998-2001, we worked on an interdisciplinary project that produced multimedia case studies designed to improve engineering education. These case studies were developed in partnership with industries and brought a real-world decision making environment into the classroom. We later expanded the case studies and developed new instructional materials that added links to show the connection between science, technology, engineering, and mathematics (STEM) education and the real-world issues. We tested their effectiveness and adaptability with freshman engineering students, current high school STEM students, and 4-H (ranging in age from nine to fourteen) students. This paper describes how we added STEM components to one case study, Della Steam Plant and provides findings from implementation of this instructional material in different classrooms. The paper concludes by emphasizing the need for development of a national digital library of STEM-based case studies.

Develop Della Case Study. We established contacts with Southern Company in creating the Della case study. The process of developing the case study involved identifying the objectives, creating discussion questions and answers, researching the theoretical STEM knowledge needed to solve the problem, and obtaining references. The case study was framed around a critical problem facing engineers, managers, and technical personnel in a company. The

Proceedings of the 2004 American Society for Engineering Education Annual Conference \& Exposition, Copyright @2004, American Society for Engineering Education 
researchers and students visited the industry and talked to the engineers and managers in order to learn about the problem first-hand. The authors recorded these conversations and later had them transcribed into textual material. This material formed the basis for the first iteration of the written case study and instructor's manual. The draft case study was reviewed by a Review Board consisting of industrial partners and faculty in engineering and business. Then it was pilot tested with students in a classroom. The case studies have been published as journal articles (Sankar et al., 2003; Sankar et al., 2000; Sankar et al., 1999; Raju and Sankar, 1998). Input from these groups was used to revise the case and create the final version. A short description of the Della case study is provided below:

\section{Della Steam Plant (Steam power plant): Severe vibration leading to shut-off of a turbine.}

This case study involved three principal managers and engineers who work at a Steam Power plant - Sam Towers, the plant manager, Lucy Stone, the OEM engineer, and Steve Potts, the engineer in charge of predictive maintenance. The Della Power Plant produces and sells electricity generated by turbine-generator units. A turbine-generator unit weighing 120,000 pounds was being restarted after a two month maintenance service. When Lucy took the unit up to a high speed for an overspeed trip test, the unit started to vibrate heavily, causing the building to shake. Many employees became apprehensive and started to move away from the unit. Fortunately, it tripped out (the trip switch was activated) and rolled to a stop. Lucy noted from shaft rider probe readings that it was a 17 mil (thousandths of an inch) overall vibration. Since this was very close to the 22 mil clearance allowed between the shaft and the bearing, she anticipated the possible breakage of some parts. She therefore recommended to Sam Towers that the unit be disassembled, the parts checked, and broken parts replaced before the unit was retested. Her recommendation would cost the company $\$ 900,000$.

Steve disagreed with Lucy's recommendation based on the readings shown by the proximity sensors he had attached to the turbine-generator unit. He diagnosed that the problem was due to an oil whip and would correct itself if the unit was run for 24 hours. He recommended to Sam Towers that the turbine-generator unit be restarted immediately. The plant was facing tight maintenance budgets, and Steve's recommendation would result in zero cost if there were no problems during restart. However, if the unit failed during restart, the company would have to replace the entire unit, leading to a potential cost of $\$ 19.5$ million.

Sam Towers, the plant manager, was in a dilemma since this was the first time his engineer and RLS engineer had disagreed on a major maintenance problem at the power plant. He had to decide whether to restart the turbine-generator unit or shut it down, taking into account financial, technical, and safety issues.

\section{Add STEM Contents to the Case Study}

Competency materials in the different STEM subject areas were developed for the case study so that students from engineering and other schools would be able to understand and analyze the case study given their educational background. Table 1 summarizes the STEM competency materials that were developed and linked with the Della case study. It also shows the extent of description of the STEM concepts by computing the number of slides (web pages)

Proceedings of the 2004 American Society for Engineering Education Annual Conference \& Exposition, Copyright @2004, American Society for Engineering Education 
that discuss a particular concept as a percentage of the total number of slides included in a case study CD-ROM.

\begin{tabular}{|c|c|c|c|c|}
\hline $\begin{array}{l}\text { Analysis } \\
\text { of case } \\
\text { Study } \\
\text { CD- } \\
\text { ROM } \\
\end{array}$ & $\begin{array}{l}\text { Science topics } \\
\text { discussed }\end{array}$ & $\begin{array}{l}\text { Technology \& } \\
\text { Engineering topics } \\
\text { discussed }\end{array}$ & $\begin{array}{l}\text { Math topics } \\
\text { discussed }\end{array}$ & $\begin{array}{l}\text { Business topics } \\
\text { discussed }\end{array}$ \\
\hline $\begin{array}{l}\text { Della } \\
\text { Steam } \\
\text { Plant (50 } \\
\text { slides) }\end{array}$ & $\begin{array}{l}\text { Electricity, Latent } \\
\text { heat, Fluid } \\
\text { viscosity, Rankine } \\
\text { Cycle (40 slides) }\end{array}$ & $\begin{array}{l}\text { Vibration, Power } \\
\text { Generation, Safety, } \\
\text { Machinery diagnostics, } \\
\text { Thermodynamics, Power } \\
\text { \& Efficiency, Energy, } \\
\text { Mechanical resonance } \\
\text { (40 slides) }\end{array}$ & $\begin{array}{l}\text { Measurement } \\
\text { systems, } \\
\text { Graphs (17 } \\
\text { slides) }\end{array}$ & $\begin{array}{l}\text { Decision Tree, Risk } \\
\text { management, Economics, } \\
\text { Supply and demand, } \\
\text { Profits, Deregulation, } \\
\text { Energy use (13 slides) }\end{array}$ \\
\hline
\end{tabular}

\section{Table 1: STEM Competency Materials Included in Della Case Study}

\section{The amount and impact of STEM and Business content in the Della Case Study}

The Della Case study, with the STEM extension, is rich in its use of multidisciplinary content. The hope is that by introducing Science, Math, Engineering/Technology, and Business content in terms of a real-world problem, students will be motivated to learn because they can see the application of that learning. The Della Case Study CD-ROM has approximately 50 web pages, with some web pages having up to 20 PowerPoint slides covering a particular topic, others incorporating videos, and others with audio. As you can see in Table 1, for each major concept Della has at least 10 web pages (including video, audio, etc.) covering that particular topic.

Additionally, every web page covered at least two of these four major topic areas. Every science and math web page was explained in relation to the main engineering/technology problem examined (Figure 2). This emphasis on relating basic science and math concepts to the engineering problem at hand, helps students better understand the relevance of basic science and math to a real-life situation. 


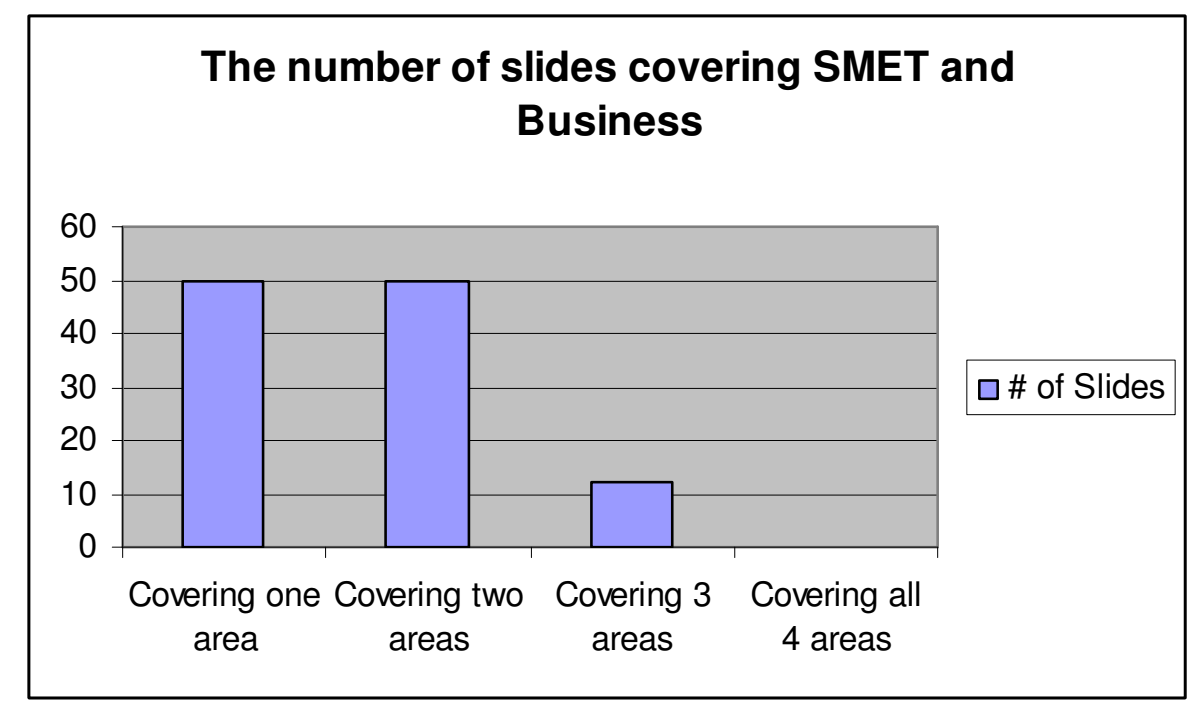

Fig. 2. Interrelationships Between the STEM Areas

In the sciences, the Della Case study covered electricity, heat and energy, physics, and chemistry (See Fig. 3). The physics concepts taught include momentum, work, statics, dynamics, force, fluid viscosity, thermodynamics, velocity and acceleration, friction, and mechanical resonance. The chemistry concepts taught include thermodynamics, latent heat, the Rankine cycle, atomic structure, and energy conversion. This case study emphasized physics concepts as well as heat and energy concepts. Students learned these topics so that they could better understand how the steam plant produces power and how the steam plant can have possible failures. For example, the Della case study explains how the vibration problems with the turbine generator at the steam plant are related to mechanical resonance, momentum, work, friction, and thermodynamics.

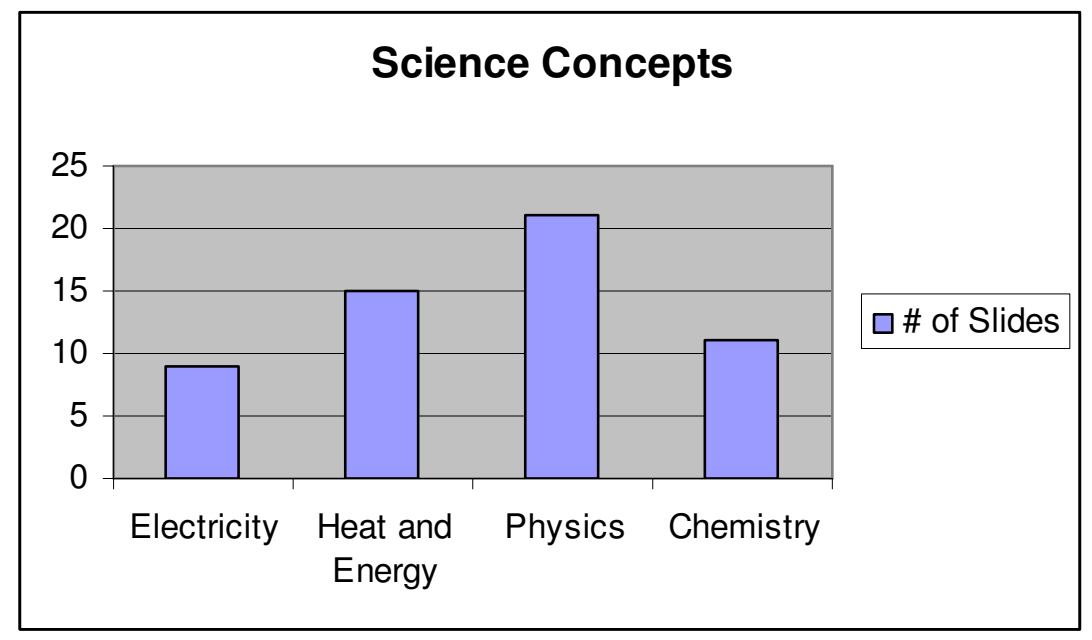

Fig. 3. Physics concepts covered

In the mathematics area, the Della case study covered Calculus, Trigonometry, Tables and Scales, Algebra, and Probability (See Fig. 4). Web pages in the STEM version of the Della case study taught students how to find derivatives, how to integrate, how to find the area of surfaces, how to use charts, how to find and apply probability statistics, and how to find 
solutions to formulas. Once these concepts were taught, the case study went on to explain how these particular topics were relevant to the problems at Della or in energy production. For example, once students learned about how to do probability problems in statistics pages, they were shown how these statistics were important to determine the failure rate of the turbine generator.

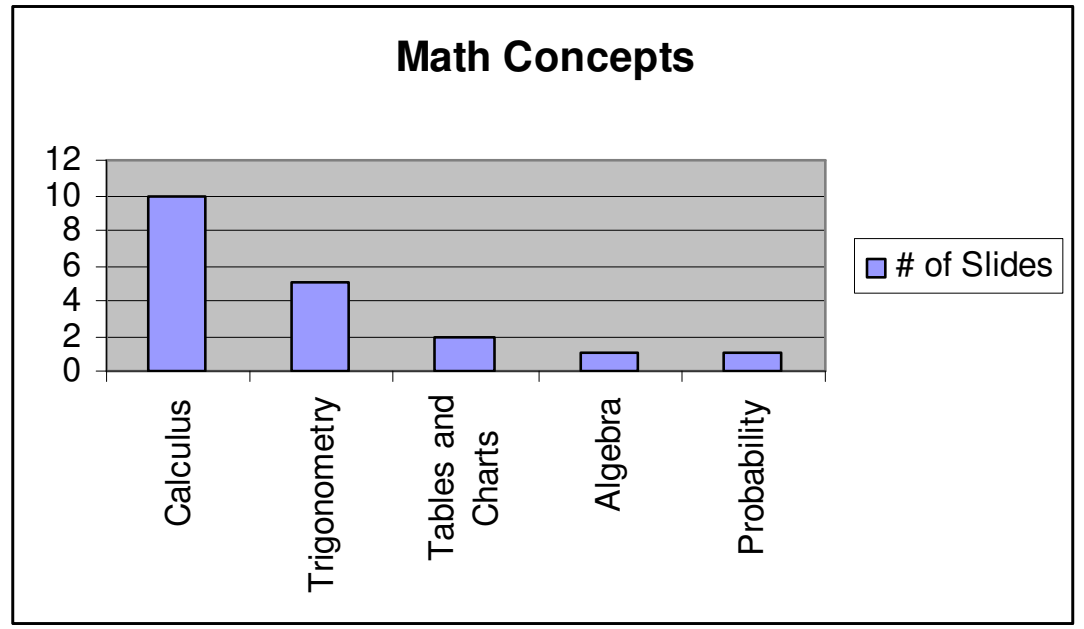

Fig. 4. Math Concepts Included in the Case Study

The Della case study strongly emphasized engineering/technology concepts, since the issue at the steam plant was a technical, engineering, problem. The main areas that the case study CD-ROM covered were vibration, power generation, safety, bearings, predictive maintenance, and machinery diagnostics (See Fig. 5). In particular, the CD-ROM focused on power generation so that students understood how a power plant worked before they learned about the problem that was happening in the plant. Each of these Engineering/Technology pages was either related to science, math, or business. One of the main focuses of this case study was how business issues are related to engineering/technology problems, for example, how deregulation of the power plant industry affected Della and the demands placed on Della for power generation.

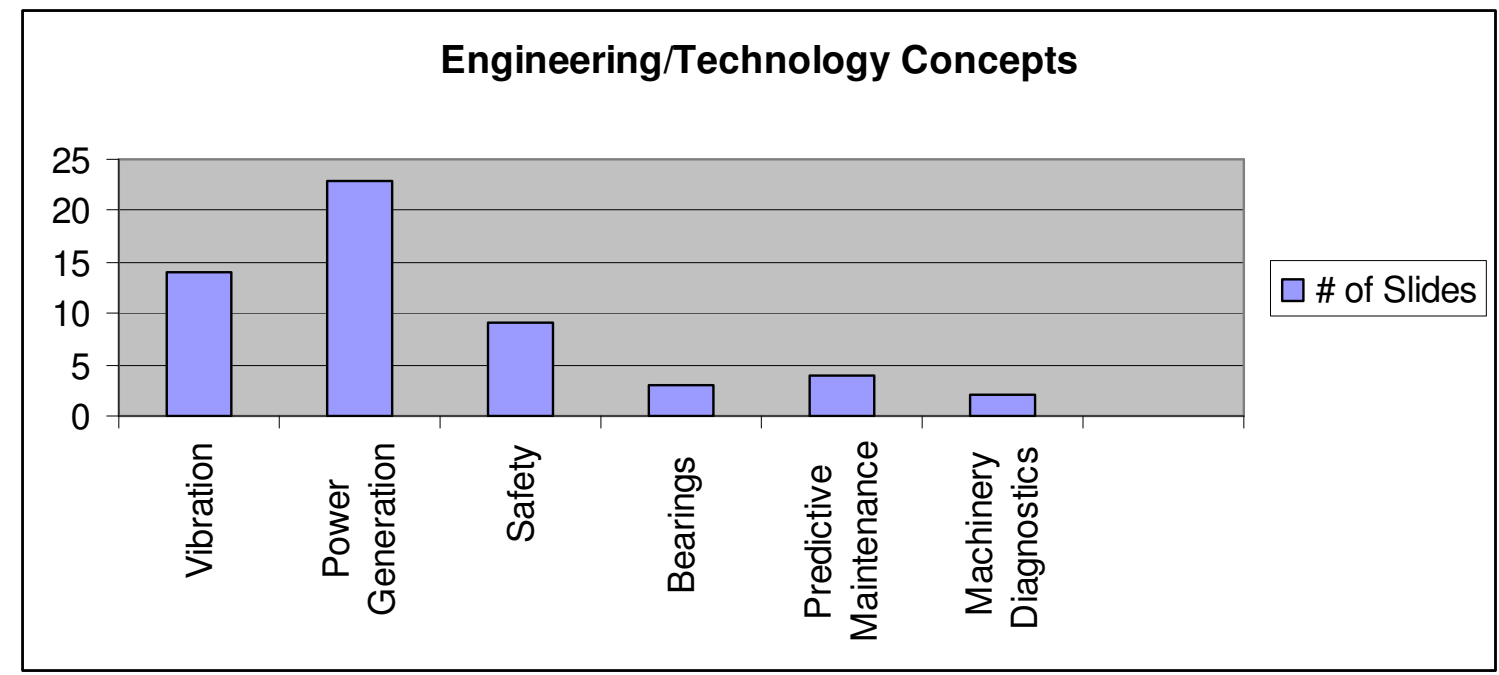

Fig 5. Engineering/Technology Concepts Used in Case Study

Proceedings of the 2004 American Society for Engineering Education Annual Conference \& Exposition, Copyright@2004, American Society for Engineering Education 
The Della Case study CD-ROM discussed the impact of Business issues on energy production and the energy industry. The Business issues that the case study discussed were economics, supply and demand, risk management, profit and loss, deregulation, energy use, and the use of decision trees (See Fig. 6). The Della case study CD-ROM had the strongest emphasis on economic issues. In particular, the case study focused on the costs associated with restarting the turbine generator at the steam plant and how those costs affect the decision to restart or delay restart. The case study also discussed the impact of deregulation on the energy industry and how high energy use influences and impacts profit in a power plant. One application-oriented business concept that Della covered was the use of decision trees in making cost based decisions. The main goal of covering these concepts was to help students understand how business issues are relevant to engineering problems and how engineering issues are relevant to making business solutions.

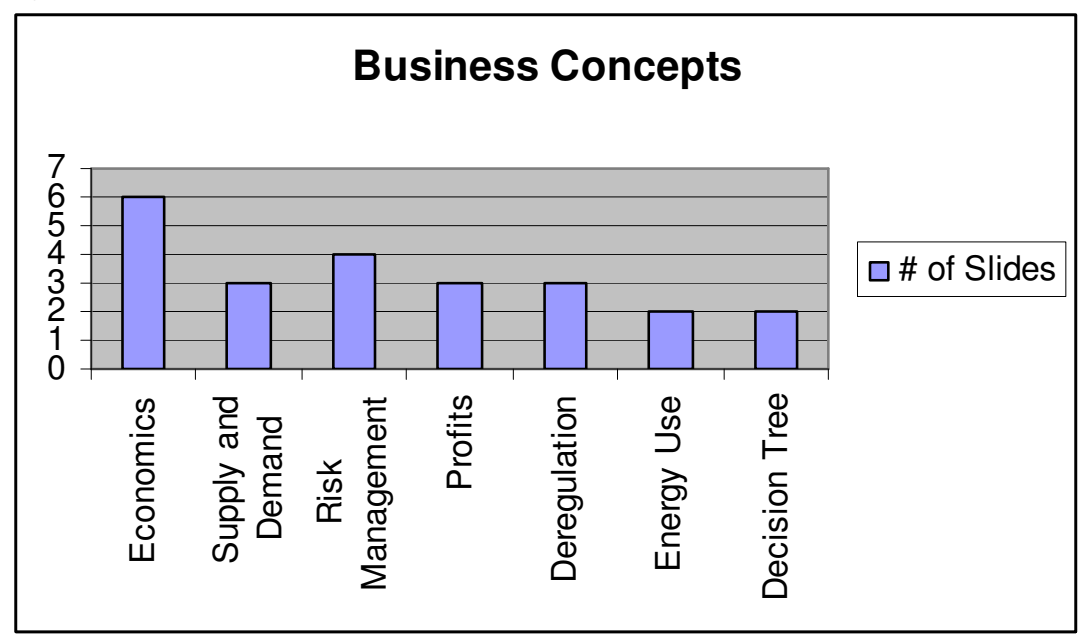

Fig. 6. Business Concepts Used in Case Study

As shown in this section, the Della Case study, with the STEM extension, brings together science, math, engineering, and business issues in the Della Steam plant turbine generator problem. Each of the concepts in science and math, including thermodynamics, calculus, etc., were applied to the vibration problem at Della or to how power is produced at Della. In addition, this section showed how Della applies the business issues involved with the power industry to the technical aspects of power production and plant failure. The Della case study provides an example of a method to teach STEM concepts using a real-world multimedia format.

\section{Administer the Case Studies in Engineering and Business Classrooms:}

During 1999-2003, the case studies have been used every semester in two engineering courses.

ENGR 1110: Introduction to Engineering is a freshman level course and ENGR 2210:

Engineering Design is a sophomore level class. In addition, the case study has been used at other universities, including the Rose-Hulman Institute, Alabama A\&M University, and Mercer University. It has also been used in a high school and in a 4-H (aged from nine to fourteen) program. 


\section{Findings from Administering Della Case Study}

The major findings of implementing the case study in classroom are: (a) the rich multidisciplinary, interactive, content-based format of the case studies encouraged undergraduate students to learn technical issues in a fun, exciting, and relevant way; and (b) high school students get excited about science provided real-world issues are brought into the classrooms. Even though the case study has been administered in many different classes, evaluation data has been reported for only a few of the classes due to space limitations. Each of these findings is described further below.

\section{STEM materials are well received by students if they are integrated with real-world case studies}

The results from class evaluations show that the STEM materials are well received by the students when they are integrated with case studies. In addition, the students completed an electronic journal consisting of nine questions that asked about their learning process. A summary of the results is also discussed in this section.

Evaluation results from the administration of the Della case study to 23 students at Auburn University and 17 students at Alabama A\&M University ( 2 classes) and their responses were obtained by a questionnaire. Analysis of the questionnaire reveals that the score fell on the positive side of the 5-point continuum on all nine constructs (interesting and exciting, important and valuable, instructionally helpful, relevant and useful, perceived skill development, selfreported learning, intrinsic learning and motivation, communication skills, and learn from fellow students). In fact, six of the nine constructs received mean ratings of 3.5 or above. The instructor felt that it was an excellent learning and teaching tool that added to the enjoyment of learning.

The case study and its STEM extensions appear to effectively combine theory with practice, as well as encourage the use of higher-order thinking skills of students - two primary objectives of this project.

\section{High school students get excited about science provided real-world issues are brought into the classrooms}

The STEM version of the Della Steam Plant case study was administered in a physics class at Tallassee High School, Tallassee, AL. Mr. Clay Hamblen documented the use of these materials in a physics classroom for his Honors undergraduate thesis. In addition, a special workshop was held for 4-H students (ages ranging from nine to fourteen) in Birmingham, AL. These studies show that high school students get excited about science once they are able to work with case study CD-ROMs that use STEM extensions

\section{Findings from Using a Case Study at a High School Level}

A physics teacher at a High School included the Della Steam Plant Case Study in his lesson plan during the Fall semester of 2001. An example of how the case is incorporated into

Proceedings of the 2004 American Society for Engineering Education Annual Conference \& Exposition, Copyright @2004, American Society for Engineering Education 
his lesson plan is for the topic of Energy. One section of material discussed the types of energy, energy conversions, and the conservation of energy.

The first lecture began with a PowerPoint presentation which listed and defined types of energy. Examples and units of energy were discussed along with the defining of transducers. The teacher then went to the Della Steam Plant Case Study CD-Rom and played the video titled "Power Generation." This instructional video discussed how power was made at the Della Steam Plant. The class was concluded with a recap of conversions and units using the STEM link on the CD-Rom.

The second lecture began with a PowerPoint presentation that defined kinetic and potential energy. Types of potential energy were discussed along with equations for kinetic and gravitational potential. The Della STEM section on the CD-Rom was then discussed to reveal how the internal energy of steam (enthalpy) is converted into kinetic energy to push the turbine. Example problems were then worked on the board.

The third and final lecture on energy began with a power point presentation on the law of conservation of energy. A pendulum example was discussed on the black board. An inclinedplane problem was then discussed on the board with the use of the STEM link on the CD.

At the conclusion of the semester, the students were then assigned to groups and required to make a final presentation similar to the university level presentations. The groups were assigned to a particular role (either that of the manager or the engineer at Della Steam Plant) and required to make a detailed presentation on that role.

Results of implementing the STEM version of Della CD was evaluated by the eight female students using a 6-item questionnaire and ranked their perceptions on 5-point Likert scale. They perceived that using a case study derived from the real world made studying Physics more interesting. They perceived a better connection between Physics and the real world. The results of student surveys showed a positive reaction to the case. The case did not take the place of high school instructors, but rather provided them with a supplement that helped solidify what the students learned in lectures.

\section{Findings from the Use of a Case Study at 4-H Camp}

The project team constructed the $4 \mathrm{H}$ Sci-Tech day camp program by incorporating recent advances in disciplinary content, research on teaching and learning, and instructional technologies into the curriculum. The day camp program offered a stimulating experience for STEM learning outside of formal classroom environment. This unique experience was fostered through use of multimedia, hands-on learning, and a community-based approach that involved a diverse mix of students, parents and $4 \mathrm{H}$ Adult Volunteers. The

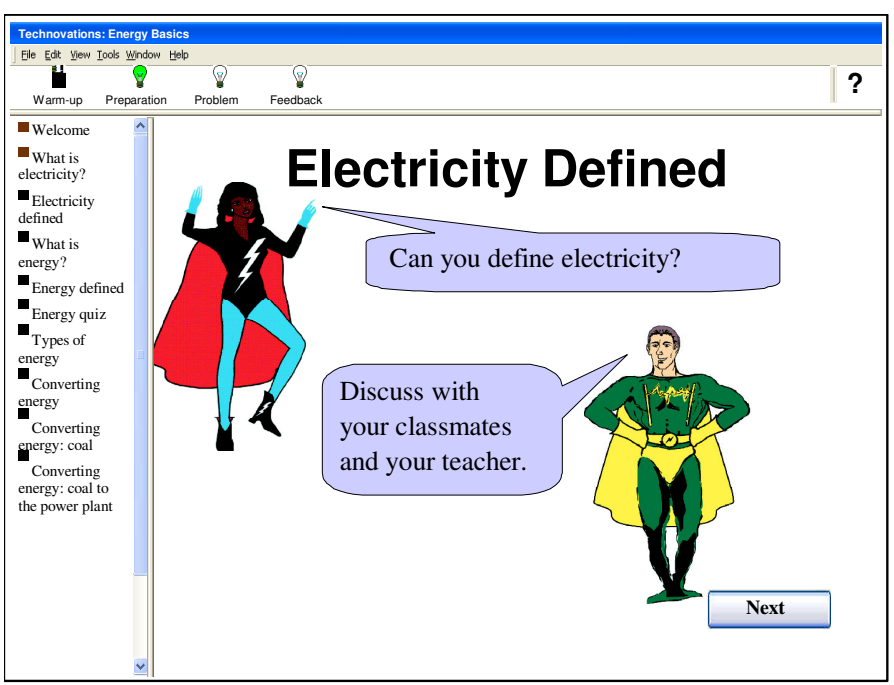

Proceedings of the 2004 American Society for Engineering Education Annual Conference \& Exposition, Copyright @2004, American Society for Engineering Education 
intent of this community-based approach was to increase interest, understanding, and interaction with STEM topics by individuals of all ages. Additionally, the project team wanted to establish a link between informal and formal education, and to stimulate parents and others to support their children's STEM learning. Ultimately, the day camp program wanted to challenge parents and community organizations to become informed proponents for high-quality, universally available STEM education.

On September $7^{\text {th }}$ 2002, ACES/4-H hosted a Sci-Tech Day Camp at the Botanical Gardens in Birmingham, Alabama. The attendees and participants consisted of students, parents, 4H Adult Volunteers, and ACES agents. The twenty-four students represented six Alabama counties (Perry, Limestone, Choctaw, Houston, Montgomery, and Randolph). The students ranged in age from nine to fourteen; ten of the students were boys; 14 were girls. Of the twentyfour students participating, four were African American. Two school teachers and three student assistants conducted instructional and hands-on learning segments of the camp. Two faculty members and one ACES/4-H coordinator managed the day camp program and its logistics.

\section{Energy Warrior Boot Camp}

Students were informed that they were participating in a Boot Camp called "Energy Warrior" and two characters "Captain Current" and "Sergeant Circuit" would lead them through an adventure that would develop their existing knowledge of STEM related to Energy. By successfully completing all segments of the day camp each student would advance to the rank of Energy Scout and receive the "Energy Warrior Boot Camp" certificate. It was planned to follow up this workshop with others so that the students could become motivated to pursue STEM education.

\section{Findings from the Implementation}

The statistical results and comments from both the students and adult leaders showed that the camp successfully met the desired educational outcomes. The tests and questionnaires were analyzed in order to determine the effectiveness of the pilot camp. Fifteen questions measured the knowledge gained by students and adults who attended on concepts of energy, physics, and information technology. We chose to do a 2 sample t-test in order to test the null hypothesis, which states that there is no difference between the results of the pre-test and post-test. The test result was significant at alpha $=.05$; thus, we can say with $95 \%$ confidence that, on average, the participants answered .24 to 3.8 more questions correctly on the post-test than on the pre-test.

This shows that the camp met the educational objective of making both the students and adults more proficient in science. Analysis of the questions related to energy showed that the students and adults had a better understanding of energy, physics, and information technology concepts. These responses show that the students became more interested in science and information technology topics. Analysis of questions related to solving problems and relating science to real-world engineering problems, also showed scores of 3 and above in a 5-point Likert scale (a scale where 1 stands for not interested, 3 for neither interested nor not interested, and 5 for strongly interested). The questions on having fun in the workshop received a very high score of 4.5 and above, showing that both the students and the adults enjoyed the camp. Questions completed by adult leaders on improvement in perceived skill development, selfreported learning, communications skills, and learned from fellow students were all above 4.0 on the 5-point Likert scale.

Proceedings of the 2004 American Society for Engineering Education Annual Conference \& Exposition, Copyright @2004, American Society for Engineering Education 


\section{Conclusions}

The development of STEM extensions to the Della Case Study and implementation at undergraduate classes, high school, and 4-H camp show that it is possible to teach STEM concepts effectively using case studies. The results from the use of the Della case study in undergraduate classrooms show that it is effective in connecting the physics and math concepts learned in other classes with real-world engineering. The next step is to develop more such case studies in other engineering disciplines and make them available to students and instructors using case study collections housed in national digital libraries.

The results from the use of Della case study in the 4-H program show the potential impact of the instructional materials developed in changing the non-formal education of young students in Alabama and at other states. If instructional materials are further developed and tested, this program could reach many more students with a positive message about the importance of science and engineering in the real-world.

The next step for this day camp program is best summarized by a comment from a 4-H adult volunteer, parent and former teacher -

"Every county in Alabama needs to have the benefit of this day camp."

The results from the use of Della case study in the high school shows that the materials appear to be very worthwhile and important in teaching physics theories. The science and math skills of our nation's high school students are incredibly important to the continued success of this nation. The use of STEM case studies in the high school classroom could play a major role in the development of our high school students and in the development of this country's intellectual capital.

Overall, the results show the need for further development of case study materials that show how learning STEM concepts is essential in solving real-world problems. A collection of such materials need to be made available to instructors and students using the national digital library initiative. Widespread use of such materials has the potential to get young students excited about pursuing careers in science and engineering.

\section{References}

Aldridge, M.D. (1994). "Professional Practice: A Topic for Engineering Research and Instruction,” Journal of Engineering Education, 83(3): July 1994, pp. 231-236.

Bok, D. Higher Learning, Cambridge: Harvard University Press, 1986.

Boyer, E. College; The Undergraduate Experience in America, New York: Harper and Row, 1987.

Cost Engineering, (1996), "Engineering at the Millennium: A New Vision," Cost Engineering, 38(7): July 1996, pp. 23-25.

Fergusson, E.S. Engineering and the Mind's Eye, Cambridge: MIT Press, 1992.

Proceedings of the 2004 American Society for Engineering Education Annual Conference \& Exposition, Copyright @2004, American Society for Engineering Education 
Hingorani, K., Sankar, C.S., and Kramer, S., (1998). "Teaching Project Management Through an InformationTechnology Based Method,” Project Management Journal, 29(1): 10-21.

Leidner, D.E., and Jarvenpaa, S.L. "The Information Age Confronts Education: Case Studies on Electronic Classrooms," Information Systems Research, 4(1), 1993, pp. 24-54.

Mbarika, V., Sankar, C.S., and Raju, P.K. (2003), "Perceived Role of Multimedia Instructional Materials on Multicriteria Technology and Engineering Decisions," Decision Sciences Journal of Innovative Education, 1(2): 225-257.

National Science Board, Communicating Science and Technology in the Public Interest: NSB-00-99, 5/4/2000.

National Science Foundation. Shaping the Future: New Expectations for Undergraduate Education in Science, Mathematics, Engineering, and Technology, Washington, DC: Directorate for Education and Human Resources, NSF96-139, 1996.

National Science Foundation, Contributions of the Social Sciences to the National Science Foundation Review of Undergraduate Education, A Workshop, February 22, 1996, National Science Foundation, Arlington, VA, 1996.

Nickerson, R.S., "The Teaching of Thinking and Problem Solving in R.J. Sternberg (eds.,)," The Teaching of Thinking and Problem Solving, New York, Academic Press, 1994.

Raju, P.K. and Sankar, C.S. (1998)., "Della Steam Plant: Should the Turbine be Shut-Off?” Case Research Journal, 18(1\&2): 133-150.

Sankar, C.S., Klesius, P., Raju, P.K., Ford, F.N. (2003). "Selection of Operating Systems for POS Terminals to Serve Business Functions at Chick-fil-A,” Journal of SMET Education: Innovations and Research, 4(1\&2):5-27.

Sankar, A., Sankar, C.S., Raju, P.K., and Dasaka, V. (2000). "Implications and Ramifications of Engineering Design of Field Joint for the Space Shuttle," Journal of SMET Education: Innovations and Research, 1(1): 37-62.

Sankar, C.S., Raju, P.K., Kler, M. (1999)., “Crist Power Plant: Planning for a Maintenance Outage,” Business Case Journal, 5(1\&2): 122-145.

Sheila T., Revitalizing Undergraduate Science: Why Some Things Work and Most Don't, Research Corporation, Tuscon, AZ, 1992.

Wulf, W.A. "The Urgency of Engineering Education Reform," The Bridge, 28(1), Spring 1998.

\section{Acknowledgments}

This research was based upon work supported by the National Science Foundation under Grant No. DUE\# 9752353, DUE\# 9950514, DUE\#0001454 and DUE\#0089036. Any opinions, findings, and conclusions or recommendations expressed in this material are those of the author(s) and do not necessarily reflect the views of the National Science Foundation. We thank Chet Plank, Chris Davis, Clay Hamblen, Daniel Seaton, Justin Cochran, Nadja Bliedung, Sean Cook, Ven Raju, and Srinivas Kumarasetty who developed the STEM connections to the case study CD-ROM discussed in this paper. All these undergraduate and graduate students were part of the LITEE project.

\section{Biographical Information}

Shivram K. Sankar worked as a undergraduate research assistant at the Laboratory for Innovative Technology and Engineering Education (LITEE) during Summers 2002 and 2003. He is a senior at the Weinberg College of Arts and Sciences at Northwestern University and has been on the Dean's list for the past two years. He is majoring in Political Science and Cognitive Science. He could be contacted at s-sankar@ northwestern.edu.

Proceedings of the 2004 American Society for Engineering Education Annual Conference \& Exposition, Copyright @2004, American Society for Engineering Education 
Dr. Chetan S. Sankar is the Thomas Walter Professor of Management at Auburn University specializing in telecommunications and Management Information Systems. Laboratory for Innovative Technology and Engineering Education (LITEE) run by Drs. Raju and Sankar with the help of an interdisciplinary team of students develops innovative instructional methods and materials that have shown to improve education of engineering, business, and technology students. He could be contacted at sankacs@auburn.edu.

Dr. P.K. Raju is the Thomas Walter Professor in the Mechanical Engineering Department at Auburn University, Director (Engineering) Auburn Industrial Extension Service, and Assistant Chairman of the Mechanical Engineering Department. He has directed and managed projects that deal with different aspects of acoustics, vibration, noise control, non-destructive evaluation, and engineering education with a total budget exceeding \$2.5 million. He could be contacted at pkraju@eng.auburn.edu.

Proceedings of the 2004 American Society for Engineering Education Annual Conference \& Exposition, Copyright @2004, American Society for Engineering Education 